DOI 10.5216/ia.v46i2.67780

\title{
EDUCAÇÃO E DIREITOS HUMANOS: ASPECTOS FUNDAMENTAIS DA DEMOCRATIZAÇÃO DA EDUCAÇÃO AOS REFUGIADOS VENEZUELANOS EM MANAUS
}

\author{
FABIANE MAIA GARCIA \\ LEANDRO HarISSON DA SiLVA VASCONCELOS \\ Diego FERNANDES PINHEIRO \\ Universidade Federal do Amazonas (UFAM), Manaus, Amazonas, Brasil
}

\begin{abstract}
REsumo: Este artigo* se propõe a analisar o atendimento educacional aos refugiados em Manaus nos anos de 2017 e 2018, como parte do processo de democratização da educação brasileira, no qual o conceito de Direitos Humanos é entendido como garantia universal dos países signatários da Declaração Universal dos Direitos Humanos (1948). O estudo é de natureza bibliográfica e documental, com bases teóricas imprescindíveis para uma compreensão consubstanciada em relação aos conceitos. Os resultados retratam a compilação dos processos, formatos e desafios no atendimento educacional aos estudantes refugiados em Manaus como parte fundamental do direito de acesso e permanência ao sistema público de ensino.
\end{abstract}

Palavras-chave: Democratização. Educação. Refugiados. Política.

\section{INTRODUÇÃO}

Este artigo apresenta um retrato da educação para refugiados venezuelanos na cidade de Manaus, capital do estado do Amazonas. Vários estados brasileiros - São Paulo, Rio de Janeiro, Mato Grosso do Sul etc. ${ }^{1}$ - acolheram refugiados venezuelanos que ingressaram no país após a crise econômica, social e política que atingiu aquela nação na segunda década do século XX. No Brasil, o refugiado precisa ser integrado à sociedade, o que também quer dizer que a educação é uma das áreas primordiais para que se faça essa incorporação.

A primeira parte deste trabalho disserta sobre Direitos Humanos, pois é o ponto essencial quando diz respeito à pessoa humana, principalmente com os que estão em vulnerabilidade social. Além disso, os marcos legais sobre o refúgio nos dizem respeito sobre a área da educação, sendo o objetivo deste trabalho analisar como a política de Direitos Humanos pode ajudar os sujeitos em situação de refúgio a serem integrados socialmente. A democratização também é assunto dessa primeira parte, pois a educação, antes restrita a poucos, torna-se ao longo do século $\mathrm{XX}$, juntamente aos direitos, uma política universal e que cada vez se torna uma conquista social. Essas questões, juntamente à problematização do refúgio, são importantes no sentido da reflexão sobre a política educacional.

Na segunda parte, disserta-se sobre o atendimento educacional aos estudantes em situação de refúgio no estado do Amazonas. Faz-se um prolegômeno histórico sobre 
a tradição do Amazonas em receber refugiados, sendo os nordestinos, atraídos pela grande riqueza da extração da borracha, um grande exemplo de assimilação e construção social. No início do século XXI, com a crise econômica e com o terremoto que abalou o Haiti, um grande quantitativo de habitantes daquele país encontrou em Manaus um lugar para recomeçar. Com a chegada dos venezuelanos, um novo desafio de integração foi lançado, sendo necessárias toda uma reflexão e ação para o seu acolhimento.

Por fim, na terceira parte, apresenta-se dados do acesso de estudantes em situação de refúgio nas escolas municipais de Manaus durante os anos de 2017 e 2018. Com a obrigação constitucional de prover educação básica a todas as pessoas que vivem em seu território, os profissionais da educação brasileira, em especial dos estados mais próximos da Venezuela, como no caso de Roraima e do Amazonas, tiveram que se reinventar para esse acolhimento educacional. Os números apontam que o quantitativo de estudantes pertencentes à família em situação de refúgio em 2017 na rede municipal é de pouco mais de 100 estudantes, já no ano seguinte eram mais de 400 estudantes, algo que pode ser explicado pela facilitação do acesso à rede pelos discentes em situação de refúgio.

\section{DIREITOS HUMANOS, DEMOCRATIZAÇÃO DO ENSINO E O REFÚGIO}

O caminho para a universalização dos Direitos Humanos é longo e para entendê-lo é necessário perpassar questões históricas, políticas, sociais e econômicas. Durante séculos a sociedade foi regulamentada por determinadas instituições sociais, a depender da realidade e da localidade, e apenas uma parte dos homens tinha direito à visibilidade. No período dominado pela Igreja Católica, por exemplo, a ideia da transitoriedade terrestre se popularizou e valorizou-se a "vida eterna": "a Igreja havia suprimido a antinomia entre Homem e sociedade, substituindo-a pela panaceia transcendente da eternidade" (MBAYA, 1997, p. 17). Essa concepção de sociedade favorecia os ricos e objetivava manter o status quo, imobilizando ao máximo as camadas mais pobres.

Embora alguns autores, como Norberto Bobbio, defendam que a gênese dos Direitos Humanos esteja no direito inglês, do século XIII, Lopes $(2011$, p. 8) assinala que "a teoria dos Direitos Humanos teve sua origem no lluminismo e no Jusnaturalismo desenvolvidos na Europa dos séculos XVII e XVIII", quando houve o entendimento, por esse grupo de intelectuais, de que todos os homens tinham "direitos inalienáveis e imprescritíveis, decorrentes da própria natureza humana e existentes independentemente do Estado" (LOPES, 2011, p. 8).

A autora, contudo, deixa claro que antes do lluminismo os conceitos de liberdade e igualdade já existiam, mas que, como já dito, essas realidades jurisdicionais estavam restritas a um grupo de pessoas privilegiadas. Tomemos como exemplo a Magna Carta, de 1215, que dava direitos aos barões e ao clero, minoria naquele tempo, e a Bill of Rights, de 1689, que marcou o fim do Absolutismo na Inglaterra (BEZERRA, 2019). Ambas as cartas fazem parte do processo histórico dos Direitos Humanos, mas não tinham um caráter universal, que viria a acontecer apenas no século XX. 
GARCIA, F. M.; VASCONCELOS, L. H. da S.; PINHEIRO, D. F.

Os direitos previstos na Magna Carta de 1215 e no Bill of Rights da Inglaterra de 1689 foram concebidos como concessões do poder soberano a um grupo determinado de pessoas, e não como direitos inerentes a todo ser humano (LOPES, 2011, p. 8, grifo do autor).

Lopes (2011) assinala a importância do Absolutismo para a conquista dos Direitos Humanos, mesmo que tal comparação possa parecer paradoxal. Segundo a autora, as lutas do povo contra o sistema estabelecido, algo que não apenas aconteceu contra o Absolutismo, mas um processo que ainda existe na atual democracia burguesa, foram importantes para que o cidadão reivindicasse o direito que era, até então, restrito a poucos. Essas lutas foram importantes na construção do Estado liberal francês e no desenvolvimento da independência das colônias inglesas na América do Norte, no século XVIII (LOPES, 2011).

A sociedade humana forjada na escravidão dos regimes coloniais, na luta de classes e, mais tarde, pelo fascismo e outras políticas que sonegavam o direito à maioria começou a perceber a necessidade da universalização dos Direitos Humanos, pois "A história dos Direitos Humanos é caracterizada pela noção de exclusividade e, mesmo no mundo atual, tais direitos tendem a funcionar em favor dos privilegiados" (MBAYA, 1997, p. 18). Finalmente, no pós-guerra, começamos uma política de universalização e de inclusão, fundamentos essenciais para o exercício das reivindicações e da inserção dos menos favorecidos nas políticas públicas:

Com a criação das Nações Unidas e a adoção dos princípios da Carta da ONU, além da Declaração Universal dos Direitos do Homem, entre outros instrumentos internacionais, finalmente foi abandonada, ao menos teoricamente, a idéia da exclusividade dos direitos humanos. Vivemos, desde 1945, um período de reconhecimento da sua universalidade e inclusividade, sendo, também, um período de reivindicações dos povos no sentido de exercerem o direito à autodeterminação como um direito dos povos e do homem (MBAYA, 1997, p. 18).

O privilégio do direito começou a ser abandonado com a criação da Organização das Nações Unidas - ONU, pois ela, além da guardiã do direito internacional é, também, a entidade responsável globalmente pela resposta às violações dos Direitos Humanos. Norberto Bobbio (1992 apud LOPES, 2011) assinala que após as atrocidades dos regimes nazista e fascista, durante a Segunda Guerra Mundial, ocorrida entre 1939 e 1945, entendeu-se a necessidade de se ter um organismo internacional que fosse um árbitro nas questões do direito para todos os cidadãos, independente do país, de raça, gênero, religião etc., pois é perigoso deixar essa responsabilidade apenas aos governos de cada Estado nacional:

A proclamação da Declaração Universal dos Direitos Humanos de 1948 foi deflagrada após as atrocidades cometidas durante a Segunda Guerra Mundial, as que evidenciaram a fragilidade e precariedade de deixar a previsão e aplicação dos direitos humanos ao arbítrio de cada Estado, sendo imprescindível a elaboração de um documento com pretensões universais que fosse capaz de 
estabelecer um mínimo de proteção a todos os seres humanos, independentemente da sua raça, origem, cor, idade, sexo, religião, nacionalidade, etc. em qualquer lugar do mundo (BOBBIO 1992 apud LOPES, 2011, p. 11).

A Declaração Universal dos Direitos Humanos é um importante instrumento para que todos os cidadãos tenham acesso a direitos básicos para sua sobrevivência, mas a lógica do capital, do descarte do trabalhador, da indústria do conflito e de lutas hegemônicas, em face do excesso de oferta de mão de obra, é a responsável por produzir refugiados. $\mathrm{O}$ trabalhador, não vendo outra solução, busca em outros lugares a saída para a sua miséria. Como pontua Karl Marx, a partir do momento em que a quantidade de trabalhadores se eleva, a concorrência entre o proletariado torna-se mais violenta, deixando-os fora do exercício da sua atividade:

\begin{abstract}
Na medida em que o número de trabalhadores se elevou, a concorrência desses entre si tornou-se tanto maior, mais inatural e mais violenta. Por isso, uma parte da classe trabalhadora (Arbeiterstand) cai, assim, necessariamente na classe de miseráveis ou mortos de fome (MARX, 2010, p. 27, grifo do autor).
\end{abstract}

No Brasil, a Carta Constitucional de 1988, redigida após vinte e um anos de ditadura militar, garante os direitos básicos para todos os brasileiros naturalizados e para os que aqui vivem em situação de refúgio. No entanto, muitos deles se encontram nas ruas das grandes cidades brasileiras mendigando nos sinais ou nas rodoviárias. O país é signatário e tem diversas políticas voltadas para o direito do sujeito em situação de refúgio, porém, a crise econômica que se abateu aqui e no mundo e a ascensão de políticas neoliberais, excludentes e anti-imigração tornaram a condição de refugiado ainda mais invisibilizada.

\title{
A DEMOCRATIZAÇÃO ESCOLAR NO BRASIL E O REFÚGIO
}

A Declaração Universal dos Direitos Humanos, de 1948, em seu artigo XXVI diz que: "Todo ser humano tem direito à instrução. A instrução será gratuita, pelo menos nos graus elementares e fundamentais. A instrução elementar será obrigatória" (ONU, 1948), universalizando o direito à educação básica, independentemente de onde vivam. No Brasil, porém, o processo de democratização começa ainda em 1824, com a primeira constituição do país, como diz Rosa et al. (2015, p. 165): "os ideais de democratização do ensino começaram a surgir a partir da Constituição Imperial de 1824, que apresentou no art. 179, § 32, o direito a "instrução primária e gratuita a todos os Cidadãos".

Esse processo intensifica-se nos anos 1930 com a mudança de projeto de país, que naquele momento evidencia a ruptura da realidade agrária aristocrática e inicia a sua transformação em uma sociedade burguesa urbana com o processo de industrialização nacional, intensificando a expansão das cidades. No começo do governo de Getúlio Vargas (1930-1945) foi criado um ministério destinado à educação e este criou o Conselho Nacional de Educação, que era o responsável pelo assessoramento 
deste órgão para as políticas públicas na área educacional: “Em 1930 foi criado o Ministério da Educação e Saúde Pública. Em 1931, houve a Reforma Francisco Campos, que criou, na letra da lei, um Sistema Nacional de Educação, e o Conselho Nacional de Educação" (ROSA et al., 2015, p. 165).

Na década de 1960, com o golpe militar, o Brasil mergulhou em um dos seus períodos mais sombrios, com a falta de liberdade de expressão, com os brasileiros não podendo votar e com a cassação de mandatos de políticos que eram contrários ao regime. Essas mudanças não passaram indiferentes à política educacional, com a reforma da lei de Diretrizes e Bases da Educação Nacional, a lei n. 5692, em 1971, e um direcionamento cada vez mais claro ao ensino tecnicista, com a formação de mão de obra para a indústria nacional que se avolumava naquele período, impulsionada pela crescente urbanização.

Com a volta dos civis à Presidência da República, em 1985, e a redemocratização do país com a nova e atual constituição, promulgada em 5 de outubro de 1988, o Brasil passou a ter uma série de direitos assegurados para toda a sua população. No seu artigo 205, a Carta Maior da República diz que a educação é um "direito de todos e dever do Estado e da família, será promovida e incentivada com a colaboração da sociedade, visando ao pleno desenvolvimento da pessoa, seu preparo para o exercício da cidadania e sua qualificação para o trabalho" (BRASIL, 1988). Esse artigo é importante para assegurar que, não importando a origem, todos têm direito à educação em solo brasileiro, sendo um importante marco legal para todos aqueles que chegam ao país.

A escola é, então, um lugar que deve ser plural, aceitando todos, não importando sua origem. Infelizmente, com as mudanças do capitalismo, principalmente após o advento do neoliberalismo nas décadas de 1970 e 1980, intensificando-se na América Latina nos anos 1990, há uma pressão cada vez mais forte para que o indivíduo se torne autossuficiente, criando sérias barreiras para aqueles que necessitam de ajuda estatal para se manterem vivos. Judith Butler (2019) discorre sobre esse processo de apropriar-se da responsabilidade pelo outro, de que é necessário urgentemente que nos afastemos do individualismo para que nos tornemos uma comunidade, não importando a origem ou condição social: "É possível ao menos pensar em mim sem esse mundo de outros? Na verdade, pode ser que, através do processo de assumir responsabilidade, o "eu" se revele, pelo menos parcialmente, um "nós"?" (BUTLER, 2019, p. 61).

Essa noção de comunidade é importante quando pensamos nos alunos na condição de refugiados. O processo da responsabilidade por parte do Estado brasileiro se tornou mais distante a partir de 2016, com ascensão de governos alinhados à direita política e cada vez mais dispostos a dificultar a permanência dos sujeitos em situação de refúgio em nosso território. Destaca-se que a escola pública continua sendo o local de formação de grande parte dos sujeitos em situação de refúgio que chegam ao Brasil, pois eles são, em sua maioria, de famílias proletárias, com baixo poder material. Em alguns países, entre eles o Brasil, os estudantes na condição de refugiados tiveram dificuldades em se incluir na rede pública de ensino pela falta de documentos ou por possuírem documentos expedidos em seus lugares de origem, como explica a ACNUR (2019):

Muitos refugiados são impedidos de participar de aulas porque deixaram para trás certificados de exames e de curso, além de documentos de identidade, quando fugiram de suas casas. Mesmo 
quando esses documentos estão disponíveis, alguns países anfitriões se recusam a reconhecer a certificação emitida no país de origem dos refugiados (ACNUR, 2019, s. p.).

Essa dificuldade de acesso, por conta da burocracia, aconteceu em Roraima quando crianças na condição de refugiadas começaram a buscar ingresso na rede pública de Boa Vista, capital do estado. Os estudantes que não tinham a documentação comprobatória eram obrigados a voltar ao primeiro ano e não cursavam o ano escolar no qual estavam na Venezuela, sendo avaliados ao final do primeiro bimestre: "Sem os documentos, as crianças vão para o $1^{\circ}$ ano para adaptação da fala e da escrita e fazem prova de nivelamento ao final de um bimestre" (PAIXÃO, 2018). Já na rede estadual, a exigência de documento para ingressar não existe.

\section{O ATENDIMENTO EDUCACIONAL AOS ESTUDANTES EM SITUAÇÃO DE REFÚGIO NO AMAZONAS: GARANTIAS LEGAIS}

O balanço do banzeiro tem uma dinâmica de movimento: vem das forças de dentro dos rios e vai à superfície gerando ondas que vão e voltam. Isso acontece também com povos e nações, pessoas e grupos que, na tentativa de sobreviver, saem de suas terras levando consigo o sonho de um dia voltar: "vão e voltam como o banzeiro". $E$ assim, nesse movimento, pode-se dizer que o estado do Amazonas é traçado, de forma histórica, em sua endogenia, ou seja, em sua formação, por pessoas que vieram de outros estados, outras cidades e que aqui chegaram para a formação de suas famílias, da busca de empregos e melhoria de vida.

A esse movimento de translado de pessoas atribui-se o conceito de imigrantes: pessoas que saem de suas terras e que em uma tentativa decisória própria compreendem que em outro estado, outro país ou em outra cidade a oportunidade de sobreviver será bem maior que em terra natal. Ao imigrante atrela-se esse conceito, pois ele é movimentado por uma decisão. O que difere do refugiado. À pessoa em situação de refúgio é dada apenas duas opções: permanece em sua terra e morre devido à condição gerada ou sai em busca de uma nova vida em outra cidade, estado ou país.

O Amazonas teve o apogeu dessa movimentação de pessoas durante o período da borracha, ou, como também é conhecido, ciclo da borracha, durante a segunda metade do século XIX e início do século XX. Portanto, essas não são pessoas em situação de refúgio, pois ele pressupõe outro aspecto social. Foram escolhas de moradia e de vida. Para que fossem configurados como pessoas em situação de refúgio, essas teriam que se enquadrar de forma terminológica aos conceitos discutidos e tipificados a partir das discussões universais, como no Tratado de Cartagena (1984) e na Convenção de Organizações das Nações Unidas (1951).

Carneiro (2012) faz um apontamento seguido de uma análise quanto aos critérios que foram tipificados ou mesmo estabelecidos ao conceito de refugiado a partir da Convenção de Organização das Nações Unidas, de 1951.

As definições de refugiados antes da Convenção de Organização das Nações Unidas de 1951 se basearam em critérios distintos para 
GARCIA, F. M.; VASCONCELOS, L. H. da S.; PINHEIRO, D. F.

definir quem é um refugiado. Este processo ocorreu no marco das soluções adotadas pela comunidade internacional para responder a crises humanitárias, produto de eventos históricos que produziriam grandes deslocamentos forçados (CARNEIRO, 2012, p. 14).

A ideia de deslocamentos forçados apresentada pela Convenção, tendo por base a análise de Carneiro (2012), toma força quando tais critérios ocupam o espaço conceitual da palavra e ação. Nesse sentido, é importante salientar que, ainda de acordo com Carneiro (2012), tal conceito nem sempre teve essa conjuntura terminológica, pois "os refugiados eram definidos de forma praticamente convencional e casuística com base em um critério grupal, tomando principalmente o fato de ser membro de um determinado grupo de pessoas privadas da proteção de seu estado de origem" (CARNEIRO, 2012, p. 14). A reformulação do conceito através da ação em que passava as pessoas em suas condições fez com que a ideia central de proteção internacional se voltasse de forma específica. Teria, portanto, a segurança internacional aqueles que:

em consequência dos acontecimentos ocorridos antes de $1^{\circ}$ de janeiro de 1951 e temendo ser perseguida por motivos de raça, religião, nacionalidade, grupo social ou opiniões políticas, se encontra fora do país de sua nacionalidade e que não pode ou, em virtude desse temor, não quer valer-se da proteção desse país [...] (CARNEIRO, 2012, p. 17).

Ainda de acordo com o autor:

A característica fundamental que diferencia a perspectiva para a definição do conceito de refugiado dos critérios anteriores é que a Convenção individualizava o refugiado, e o critério se centra na pessoa do refugiado. Aqui o refugiado (a) é um ser concreto que tem uma raça professa, uma crença religiosa, tem uma nacionalidade, pertence a um grupo social ou sustenta determinadas opiniões de seu estado de origem, ou este estado não pôde e não pode protegê-lo (CARNEIRO, 2012, p. 17).

Diante dessa discussão conceitual e de sua aplicação a partir das garantias universais específicas aos países signatários, é possível compreender que os que estão presentes no estado do Amazonas, em específico, são pessoas em situação de refúgio. Tanto os haitianos quanto os venezuelanos são considerados como pessoas em situação de refúgio. Ambos com motivos distintos, mas com a mesma essência do conceito e terminologia.

Ao trabalhar a especificidade do estudo, volta-se, portanto, à questão aos venezuelanos, que, de modo geral, são vistos pelas ruas da cidade e que em grande número se fazem presentes. Não que os haitianos não sejam ou não tenham impacto social no presente cenário, mas estes já conseguiram sua estabilidade e sua forma de sobreviver.

A partir de uma análise social e histórica, as ações que dão dignidade e formação de caráter humano positivo dão margens a compreender o fato de existir uma diferença entre os povos que chegam em situação de refúgio, e em específico os 
haitianos, que chegam com uma carga cultural muito mais diversificada em relação aos venezuelanos. Tal diferença se dá pelo fato do processo endógeno cultural ser diferente e pelo movimento dinâmico histórico.

Ao caminhar pelas ruas da capital amazonense, Manaus, observa-se sem dificuldades crianças pelas ruas a pedir dinheiro nos semáforos da cidade sob o forte sol, enquanto seus responsáveis estão sentados à sombra. As principais indagações a serem feitas quando se vê essa imagem são: Por que estão fora da escola? Por que permitimos que as crianças fiquem ao semáforo pedindo dinheiro?

Para a obtenção de uma compreensão precisa e consubstancial quanto a esses fatores observados, dirigimo-nos, tanto a convite quanto a impulso da pesquisa, à Secretaria Municipal da Mulher, Assistência Social e Cidadania da Prefeitura de Manaus. Diversas questões foram levantadas, diversos assuntos foram abordados, mas apresentamos de forma específica as seguintes perguntas que eram, a princípio, as principais ideias da reunião: quantitativo de matrículas realizadas pela Secretaria Municipal de Educação quanto aos estudantes em situação de refúgio: haitianos e venezuelanos. Em relação aos venezuelanos, visto que são mais recentes.

A Secretaria Municipal de Educação nos disponibilizou o quantitativo referente aos anos de 2017-2018. Tentamos, então, a partir de uma análise, compreender a função social da escola, mas também a ação do estado em relação ao atendimento educacional aos estudantes venezuelanos em situação de refúgio na cidade de Manaus. O atendimento educacional aos estudantes em situação de refúgio está garantido na legislação brasileira e nos acordos internacionais dos quais o Brasil está participando. Segundo Silva (2012):

\begin{abstract}
- Brasil precisa avançar mais na questão global de receber e reassentar refugiados, visto que o país ainda está em processo de construção de suas políticas públicas voltadas ao tema mais geral dos direitos humanos, e para os refugiados em particular. Tanto a legislação nacional quanto a realização de políticas concretas sobre o assunto têm muito ainda a ser aperfeiçoado (SILVA, 2012, p. 142).
\end{abstract}

A educação é um direito de todos e deve atender a todos, sem distinção de raça, religião, crença ou concepções políticas e/ou filosóficas. Deve atender também e receber como ação comum todos aqueles que dela necessitarem, estando eles ou não em situação de refúgio. A busca de soluções para os refugiados no Brasil e no mundo é mais do que nunca um problema de todas as comunidades, sejam nacionais ou internacionais (SILVA, 2012, p. 141).

A realização do atendimento educacional aos estudantes em situação de refúgio tem sido executada também por base do Plano Municipal de Educação Lei no 2.000 , de 24 de junho de 2015, onde pode-se observar o artigo $2^{\circ}$, que afirma: II Universalização do atendimento escolar; III - superação das desigualdades educacionais, com ênfase na promoção da cidadania e na erradicação de todas as formas de discriminação.

Sobre o primeiro parágrafo do Plano, fica evidente que a ideia de um atendimento educacional não se limita apenas aos estudantes nativos, mas sim a uma 
GARCIA, F. M.; VASCONCELOS, L. H. da S.; PINHEIRO, D. F.

universalização educacional. Percebe-se, portanto, que o Plano Municipal de Educação de Manaus não escolhe quem este deve ou não atingir e sim que deve atingir a todos. $O$ segundo parágrafo do Plano Municipal de Educação é mais específico quanto à realização do atendimento educacional. A afirmativa está em superar as desigualdades educacionais, com ênfase na promoção da cidadania e na erradicação de todas as formas de discriminação.

Esse ponto dentro do Plano Municipal de Educação apresenta uma possibilidade da vivência às diferenças, ao incomum. Uma possibilidade ao estudante que não é próprio da língua nativa do país, que é de outra realidade. Trata-se, portanto, da parte da erradicação de todas as formas de discriminação. A xenofobia não acontece somente em casos de xingamentos ou ódio a partir de agressões físicas e verbais, mas também quando a escola se nega a fazer a matrícula do estudante por ser de outro país.

A partir da ação do estado quanto ao atendimento educacional aos estudantes em situação de refúgio, há o estabelecimento de normativas que dão garantias de permanência e condições de usufruto ao sistema educacional brasileiro: matrículas institucionais, passagem estudantil e outros subsídios que também são garantidos a um estudante nativo. Levando em consideração essas garantias, é possível, a partir de uma análise, estabelecer relações entre o que está tipificado e a ação do Estado.

A partir da redemocratização do país, é possível que, entre todas as condições sociais, as tipificações de cunho educacional sejam levadas em consideração de modo específico na Declaração Universal dos Direitos Humanos, de 1948; na Constituição Federal Brasileira, de 1988; na Lei de Diretrizes e Bases da Educação Nacional, de 1996; no Estatuto da Criança e do Adolescente, de 1990; e na Lei do Refugiado, de 1997. Todos esses documentos servem de embasamento para uma discussão entre o plano da idealidade e o plano da realidade. Segundo Garcia (2015), o direito assegurado na forma da lei não garante, necessariamente, o efetivo atendimento das previsões estabelecidas, pois muitas vezes fica restrito ao manifesto como parte da política pública.

Quadro 1 - As garantias legais que amparam o atendimento educacional aos estudantes venezuelanos em situação de refúgio em Manaus 


\begin{tabular}{|c|c|c|c|}
\hline \multicolumn{4}{|c|}{ As garantias legais de acesso e permanência na escola } \\
\hline 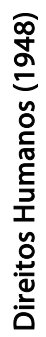 & $\begin{array}{l}\text { Art. } 2^{\circ} \text { Todo ser humano tem } \\
\text { capacidade para gozar os direitos e as } \\
\text { liberdades estabelecidos nesta } \\
\text { Declaração, sem distinção de qualquer } \\
\text { espécie, seja de raça, cor, sexo, língua, } \\
\text { religião, opinião política ou de outra } \\
\text { natureza, origem nacional ou social, } \\
\text { riqueza, nascimento, ou qualquer } \\
\text { outra condição. }\end{array}$ & 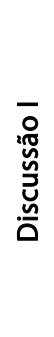 & $\begin{array}{l}\text { No tocante a essas garantias universais, } \\
\text { ninguém será privado de gozar de suas } \\
\text { capacidades, liberdade e autonomia. } \\
\text { Fazendo referência ao âmbito escolar, } \\
\text { os alunos refugiados têm por direito o } \\
\text { atendimento garantido. }\end{array}$ \\
\hline 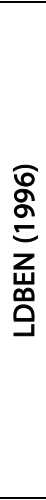 & $\begin{array}{l}\text { Art. } 2^{\circ} \text { - A educação, dever da família e } \\
\text { do Estado, inspirada nos princípios de } \\
\text { liberdade e nos ideais de } \\
\text { solidariedade humana, tem por } \\
\text { finalidade o pleno desenvolvimento } \\
\text { do educando, seu preparo para o } \\
\text { exercício da cidadania e sua } \\
\text { qualificação para o trabalho. } \\
\text { Art. } 3^{\circ} \text { - O ensino será ministrado com } \\
\text { base nos seguintes princípios: I - } \\
\text { igualdade de condições para o acesso } \\
\text { e permanência na escola; [...] XII - } \\
\text { consideração com a diversidade } \\
\text { étnico-racial. }\end{array}$ & 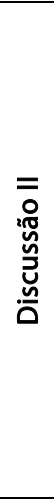 & $\begin{array}{l}\text { Aponta-se um número expressivo do } \\
\text { acesso e permanência através dos } \\
\text { dados obtidos na Secretaria de } \\
\text { Educação de Manaus, onde cerca de } \\
402 \text { de estudantes venezuelanos e } \\
\text { haitianos que estão matriculados em } \\
\text { escolas municipais de ensino no ano de } \\
2018 \text { de } 4 \text { a } 14 \text { anos. Atendendo assim, } \\
\text { portanto, todas as áreas da cidade. }\end{array}$ \\
\hline 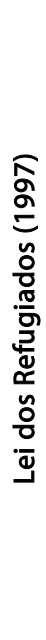 & $\begin{array}{l}\text { Art. 1०: I - devido a fundados temores } \\
\text { de perseguição por motivos de raça, } \\
\text { religião, nacionalidade, grupo social } \\
\text { ou opiniões políticas encontre-se fora } \\
\text { de seu país de nacionalidade e não } \\
\text { possa ou não queira acolher-se à } \\
\text { proteção de tal país; } \\
\text { II - Não tendo nacionalidade e } \\
\text { estando fora do país onde antes teve } \\
\text { sua residência habitual, não possa ou } \\
\text { não queira regressar a ele, em função } \\
\text { das circunstâncias descritas no inciso } \\
\text { anterior; } \\
\text { III - devido a grave e generalizada } \\
\text { violação de Direitos Humanos, é } \\
\text { obrigado a deixar seu país de } \\
\text { nacionalidade para buscar refúgio em } \\
\text { outro país. }\end{array}$ & 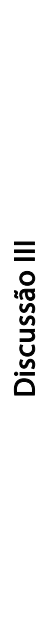 & $\begin{array}{l}\text { A oferta da Educação se concretiza não } \\
\text { em sua totalidade, mas em } \\
\text { porcentagem de ação. No Estado do } \\
\text { Amazonas, território nacional brasileiro } \\
\text { que mais recebe os refugiados, conta } \\
\text { dentro de sua rede de ensino, } \\
\text { matrículas realizadas para ingressar } \\
\text { como alunos nas escolas públicas } \\
\text { municipais. Mais de } 700 \text { estudantes } \\
\text { venezuelanos e haitianos estão } \\
\text { matriculados nas escolas da rede } \\
\text { pública de ensino no Amazonas. Ao } \\
\text { todo, } 448 \text { estão inseridos em escolas } \\
\text { municipais da capital e } 322 \text { em } \\
\text { unidades de ensino da rede estadual. } \\
\text { Em } 2017 \text {, eram } 435 \text { estudantes do Haiti } \\
\text { e da Venezuela em todo estado. }\end{array}$ \\
\hline
\end{tabular}

Fonte: Elaborado pelos autores, 2020. 
GARCIA, F. M.; VASCONCELOS, L. H. da S.; PINHEIRO, D. F.

A partir dessa discussão profícua dos presentes normativos que amparam a permanência e o acesso dos estudantes em situação de refúgio ao sistema escolar da rede municipal de ensino de Manaus, pode-se compreender que ainda há muito que se fazer quanto ao cumprimento desses normativos, visto que o número de matrículas ainda é muito distante dos reais dados obtidos, os quais serão discutidos posteriormente.

A levar em consideração a presente análise, o Estado, enquanto instrumento de democratização do ensino, não alcança as necessidades das demandas educacionais, tanto em virtude de uma debacle formativa dos processos quanto às condições e estruturas formativas continuadas dos professores. Antes de adentrarmos nos dados municipais, é necessário adotarmos uma dinâmica linear, a qual consiste em analisar os dados do país e depois especificar os dados municipais.

\section{A DEMOCRATIZAÇÃO DO ENSINO A PARTIR DO ACESSO DE ESTUDANTES EM SITUAÇÃO DE REFÚGIO NAS ESCOLAS MUNICIPAIS DE MANAUS NOS ANOS DE 2017-2018}

O município de Manaus apresenta inquietações inerentes ao atendimento educacional aos estudantes em situação de refúgio. Visto que a chegada desses se deu de forma inesperada, o estado, enquanto agente de oferta à educação, teve que se reinventar quanto à educação plural e universal, uma vez que uma demanda de estudantes em situação de refúgio que sofreu a debacle política-economia se fez presente no município. Compreender e, até mesmo, estabelecer relações entre o plano ideal e o plano real necessita de uma busca incansável quanto à ideia da ação daqueles que estão responsáveis pela execução legislativa e executiva. Faz-se, portanto, uma exclamativa a um aspecto específico: a educação.

O Brasil não recebe refugiados apenas por ter como axiologia a solidariedade, igualdade e justiça; mas os recebe em seu território por também ser integrante de um acordo humanitário entre países signatários. Logo, o país tem como dever o recebimento daqueles que estão em situação de refúgio, pois concorda com as tipificações estabelecidas na Convenção do Estatuto dos Refugiados de 1951 e da Declaração de Cartagena de 1984.

A universalização, tal qual a superação de desigualdades educacionais, são características de um processo democrático de ensino. Democratizar o ensino é ofertar vagas educacionais a todos sem distinção de raça, condição social ou qualquer aspecto de convicção. $O$ ensino deve ser plural em seu atendimento. O Brasil oferta vagas e destina matrículas de modo específico às pessoas em situação de refúgio, sem negar seus meios necessários de acesso e permanência.

Através da Secretaria Municipal de Educação de Manaus - SEMED, obtivemos os dados específicos quanto ao atendimento educacional aos estudantes em situação de refúgio na cidade. Neste obtido, a única objeção está na não especificação de quantos estudantes são haitianos e quantos são venezuelanos. Mas, de modo geral, o documento pode ser considerado de forma significativa, pois nos revela um número expressivo no ano de 2017 de matrículas de estudantes em situação de refúgio. 
Tabela 1: Quantitativo de estudantes Venezuelanos e Haitianos do Ensino Fundamental Regular, 2017.

\begin{tabular}{|c|c|c|c|c|c|c|c|c|c|c|}
\hline \multirow{2}{*}{ DDZ } & \multicolumn{5}{|c|}{ ANOS INICIAIS } & \multicolumn{4}{|c|}{ ANOS FINAIS } & \multirow{2}{*}{ TOTAL } \\
\hline & 12 ANO & 29 ANO & 3․ ANO & $44^{\circ}$ ANO & 5? ANO & 6? ANO & 79 ANO & 8? ANO & 99 ANO & \\
\hline$\overline{\text { DDZSUL }}$ & 14 & 11 & 4 & 7 & $=$ & $=$ & - & 1 & 1 & 38 \\
\hline DDZ OESTE & 11 & 8 & 5 & 4 & 7 & 2 & 2 & - & 1 & 40 \\
\hline DDZ NORTE & 5 & 10 & 2 & 1 & 2 & 2 & 1 & 1 & - & 24 \\
\hline DDZ CENTRO-SUL & 7 & 4 & 2 & 1 & 1 & 1 & 2 & - & 1 & 19 \\
\hline DDZ LESTE I & 9 & 9 & 9 & 4 & 5 & 1 & 2 & 2 & 1 & 42 \\
\hline DDZ LESTE ॥ & - & 1 & - & 2 & - & - & - & - & - & 3 \\
\hline DDZ RURAL & - & 2 & - & - & - & - & - & - & - & 2 \\
\hline TOTAL & 46 & 45 & 22 & 19 & 15 & 6 & 7 & 4 & 4 & 168 \\
\hline
\end{tabular}

Fonte: SEMED/DEPLAN/SIGEAM/DIE, 2019

Os números presentes nessa primeira tabela constam em uma separação de dados por Divisão Distrital Zonal- DDZ, sendo que Manaus é dividida em sete divisões educacionais. A zona com maior número é a Leste I, em que existem cerca de 42 alunos em situação de refúgio, os números se referem aos discentes que estavam, em 2017, do $1^{\text {a }}$ ao $9^{a}$, com idades entre 6 a 14 anos. Este número provavelmente aumentou com a vinda em massa de pessoas em situação de refúgio no ano seguinte e com o processo facilitador de reconhecimento de documentos, de acesso e permanência.

A segunda zona em que o número é elevado concentra-se na Zona Oeste, com uma diferença de duas matrículas a menos. A possibilidade dessa zona ser o epicentro no ano de 2018 é muito grande, em virtude de um número maior de escolas e com capacidade ampla e a desburocratização do acesso à rede Municipal de ensino. Segue próxima tabela:

Tabela 2: Quantitativo de estudantes Venezuelanos e Haitianos do Ensino Fundamental Regular, 2018.

\begin{tabular}{|c|c|c|c|c|c|c|c|c|c|c|}
\hline \multirow{2}{*}{ DDZ } & \multicolumn{5}{|c|}{ ANOS INICIAIS } & \multicolumn{4}{|c|}{ ANOS FINAIS } & \multirow[b]{2}{*}{ TOTAL } \\
\hline & 12 ANO & 29 ANO & 32 ANO & 42 ANO & 5: ANO & $6 \%$ ANO & $7 \%$ ANO & $8 \cong$ ANO & 90 ANO & \\
\hline$\overline{\text { DDZSUL }}$ & 35 & 21 & 20 & $\overline{5}$ & 9 & $\overline{2}$ & 1 & $\overline{1}$ & $\overline{2}$ & 96 \\
\hline DDZ OESTE & 29 & 22 & 14 & 14 & 8 & 4 & 10 & 2 & 2 & 105 \\
\hline DDZ NORTE & 13 & 6 & 12 & 4 & 6 & 2 & 2 & 1 & 1 & 47 \\
\hline DDZ CENTRO-SUL & 16 & 13 & 5 & 3 & 4 & 3 & 2 & 1 & - & 47 \\
\hline DDZ LESTE I & 19 & 16 & 10 & 9 & 5 & 8 & 2 & 4 & 1 & 74 \\
\hline DDZ LESTE ॥ & 8 & 1 & 3 & 1 & 6 & 4 & 3 & 1 & - & 27 \\
\hline DDZ RURAL & - & $=$ & 2 & 1 & 1 & 1 & 1 & - & - & 6 \\
\hline TOTAL & 120 & 79 & 66 & 37 & 39 & 24 & 21 & 10 & 6 & 402 \\
\hline
\end{tabular}

Fonte: SEMED/DEPLAN/SIGEAM/DIE, 2019.

Há uma diferença no quantitativo de matrículas realizadas durante o ano de 2018 nas escolas municipais de Manaus. Em 2017, a zona Leste concentrava o maior número de matrículas de estudantes haitianos e venezuelanos, enquanto a zona Oeste marcava a segunda posição, com 40 matrículas. Por consequência da chegada de um maior número de pessoas em situação de refúgio, fica evidente que esses números sofrem alterações quanto à quantidade de matrículas institucionais na rede de ensino do município de Manaus. 
GARCIA, F. M.; VASCONCELOS, L. H. da S.; PINHEIRO, D. F.

\section{CONSIDERAÇÕES FINAIS}

A construção do estudo intitulado: "Educação e Direitos Humanos: aspectos fundamentais da democratização aos refugiados venezuelanos em Manaus" teve seu princípio a partir de uma vertente da pesquisa de doutorado em Educação na Universidade Federal do Amazonas, com a pretensão de analisar e discutir os normativos legais que amparam a permanência e a execução da ação do estado enquanto provedor da educação para que assim se democratize o sistema de ensino.

Compreender a presente situação de refúgio na capital amazonense engendra uma análise que possibilite ideias iniciais que coadunem com os fenômenos sociais que, de modo único, são permeados na sociedade. A relação do Estado brasileiro com as crises econômicas mundiais tem ganhado relevância devido à ação que tem sido realizada no atendimento educacional aos estudantes em situação de refúgio, entre outras ações que corroboraram para um engrandecimento da visibilidade internacional no ano de 2016.

Democratizar o ensino a partir do atendimento educacional aos estudantes em situação de refúgio é uma das atividades que tem sido válidas ao processo legal da federação brasileira. Nesse sentido, compreende-se que toda a questão da execução do Estado está inerentemente ligada a uma ação comum: atender e garantir a permanência dos estudantes em situação de refúgio.

A Educação, sendo um dever da família e do Estado a todos, como garante a Constituição federal brasileira (1988) e a Lei de Diretrizes e Bases da Educação Nacional, lei 9.394/96, requer uma nova dinâmica quanto à ação do fazer de um atendimento educacional aos estudantes em situação de refúgio. Nesse sentido, realizar o atendimento educacional por base dos normativos legais brasileiros necessita também fazer alterações nos modos operantes, visto que há a necessidade da compreensão entre as línguas, os meios de comunicação, a interação entre os demais estudantes da turma, o próprio reconhecimento de datas comemorativas do país em questão. Todas essas possibilidades dão corpo e significado para um processo de uma aprendizagem significativa.

Portanto, possibilidades e maneiras de realizar um ato pedagógico dentro da realidade dos que chegam em situação de refúgio e que demandam um novo olhar se somam às condições reais da educação pública brasileira. Além da estrutura, deve-se também atentar para uma comunicação entre professor e aluno para a troca de saberes, pontos de início da construção de uma sociedade plural.

Artigo recebido em: 18/02/2021

Aprovado para publicação em: 28/05/2021

EDUCATION AND HUMAN RIGHTS: FUNDAMENTAL ASPECTS OF THE DEMOCRATIZATION OF EDUCATION FOR VENEZUELAN REFUGEES IN MANAUS

ABSTRACT: This paper proposes to analyze the educational assistance to refugees in Manaus in the years 2017 and 2018, as part of the democratization process of Brazilian education, in which 
the human rights perspective is interpreted as a universal guarantee by the signatory countries of the Universal Declaration of Human Rights (1948). The research is both bibliographic and documental, based on theoretical principles which are indispensable for a substantiated understanding of the concepts. The results reflect the compilation of processes, formats, and challenges involved in providing educational care to refugee students in Manaus as a fundamental part of their right to access and remain in the public education system.

KEYWORDS: Democratization. Education. Refugees. Policy.

\section{EDUCACIÓN Y DERECHOS HUMANOS: ASPECTOS FUNDAMENTALES DE LA DEMOCRATIZACIÓN DE} LA EDUCACIÓN PARA LOS REFUGIADOS VENEZOLANOS EN MANAUS

RESUMEN: Este artículo tiene como objetivo analiza la asistencia educativa a los refugiados en Manaus en los años 2017 y 2018, como parte del proceso de democratización de la educación brasileña, en él, el concepto de derechos humanos se entiende como garantía universal de los países signatarios de la Declaración Universal de Derechos Humanos. (1948). El estudio es de carácter bibliográfico y documental, con bases teóricas imprescindibles para una comprensión fundamentada de los conceptos. Los resultados retratan la recopilación de procesos, formatos y desafíos en la asistencia educativa a estudiantes refugiados en Manaus como parte fundamental del derecho de acceso y permanencia al sistema educativo público.

PALABRAS CLAVE: Democratización. Educación. Refugiados. Política.

NOTA

* O presente estudo foi financiado pela Coordenação de Aperfeiçoamento de Pessoal de Nível Superior - CAPES e pela Fundação de Amparo à Pesquisa do Estado do Amazonas - FAPEAM.

1 - Cf. https://www.acnur.org/portugues/2020/01/07/interiorizacao-traz-novas-perspectivas-aosvenezuelanos-no-brasil/.

\section{REFERÊNCIAS}

ACNUR. Educação para refugiados em crise: mais da metade das crianças refugiadas em idade escolar do mundo não recebe educação. ACNUR. 2019. Disponível em: $<$ https://www.acnur.org/portugues/2019/09/04/educacao-para-refugiados-em-crisemais-da-metade-das-criancas-refugiadas-em-idade-escolar-do-mundo-nao-recebeeducacao/>. Acesso em: 12 jun. 2020.

BEZERRA, J. A. Carta de Direitos Inglesa (BILL OF RIGHTS, 1689): Um Importante Documento na Constituição dos Direitos Humanos. Âmbito Jurídico, 2019. Disponível 
GARCIA, F. M.; VASCONCELOS, L. H. da S.; PINHEIRO, D. F.

em: <https://ambitojuridico.com.br/edicoes/revista-174/carta-de-direitos-inglesa-bill-ofrights-1689-um-importante-documento-na-constituicao-dos-direitos-humanos-2/>. Acesso em: 11 jun. 2020.

BRASIL. Constituição da República Federativa do Brasil, de 5 de outubro de 1988. Disponível em: <http://www.planalto.gov.br/ccivil_03/constituicao/constituicao.htm>. Acesso em: 20 jun. 2020.

BRASIL. Lei n. 9.394, de 20 de dezembro de 1996. Institui as Diretrizes e Bases da Educação Nacional, Brasília, DF, 20 de dez. 1996. Disponível em: $<$ http://www.planalto.gov.br/ccivil_03/leis/19394.htm>. Acesso em: 20 jun. 2020.

BRASIL. Lei no 9.474, de 22 de julho de 1997. Lei dos Refugiados. Brasília: Senado Federal, 1997. Disponível em: <http://www.planalto.gov.br/ccivil_03/LEIS/L8069.htm>. Acesso em: 10 jun. 2019.

BUTLER, J. Quadros de Guerra: quando a vida é passível de luto? Rio de Janeiro: Civilização Brasileira, 2019.

CARNEIRO, W. P. A declaração de Cartagena de 1984 e os desafios da proteção internacional dos refugiados, 20 anos depois. In: SILVA, C. A. S. Direitos humanos e refugiados. Dourados: Ed. UFGD, 2012. p. 14-17.

Declaração de Cartagena 1984. Disponível em: <https://repositorioaberto.up.pt/bitstream/10216/111036/2/256342.pdf>. Acesso em: 15 maio 2020.

Declaração Universal dos Direitos Humanos. Adotada e proclamada pela Assembleia Geral das Nações Unidas (resolução 217 A III) em 10 de dezembro 1948. Disponível em: <https://www.unicef.org/brazil/pt/resources_10133.htm>. Acesso em: 15 maio 2020.

GARCIA, F. M. Escola, democracia e autonomia: uma análise das políticas e práticas no cotidiano escolar. Braga: Universidade do Minho. Instituição de Educação, 2015.

LOPES, A. M. D. A era dos direitos de Bobbio: entre a historicidade e a atemporalidade. Revista de Informação Legislativa, Brasília: Senado Federal, ano 48, n. 192, p. 7-19, out./dez. 2011.

MANAUS. Quantitativo de estudantes Venezuelanos e Haitianos do Ensino Fundamental Regular. Secretaria Municipal de Educação de Manaus SEMED/DEPLAN/SIGEAM/DIE, 2019. Acesso em: 5 de mai. 2019.

MARX, K. Manuscritos econômicos-filosóficos. São Paulo: Boitempo, 2010.

MBAYA, E. Gênese, evolução e universalidade dos direitos humanos frente à diversidade de culturas. Estudos Avançados, São Paulo, v. 11, n. 30, p. 17-41, maio/ago. 1997. 
PAIXÃO, E. Em busca de um lar: os desafios dos refugiados venezuelanos na procura por casa e escola em Roraima. Revista Nova Escola, abril de 2018. Disponível em: https://novaescola.org.br/conteudo/11647/em-busca-de-um-lar. Acesso em: 20 jan. 2021.

ROSA, C. M. et al. Expansão, Democratização e a Qualidade da Educação Básica no Brasil. Poíesis Pedagógica, Catalão-GO, v.13, n.1, p. 162-179, jan./jun. 2015.

SILVA, C. A. S. da. (org.). Direitos Humanos e refugiados. Dourados: Ed. UFGD, 2012.

Fabiane Mala Garcia: Docente do Programa de Pós-graduação em Educação PPGE/UFAM - Linha de Educação, Políticas Públicas e Desenvolvimento Regional. Doutora em Educação pela Universidade de Minho - Portugal (2015), mestra em Sociedade e Cultura na Amazônia - UFAM (2005), com graduação em PEDAGOGIA pela Universidade Federal do Amazonas (1995). Professora Adjunto IV da Universidade Federal do Amazonas, Coordenadora do Programa de Pós-graduação em Educação, Coordenadora do Forpred Nacional e professora do Curso de Pedagogia. Orcid: https://orcid.org/0000-0003-0121-0416

E-mail: fgarcia@ufam.edu.br

Leandro Harisson da Silva Vasconcelos: Doutorando em Educação, na linha de Educação, Políticas Públicas e Desenvolvimento Regional, pelo Programa de Pósgraduação em Educação, PPGE/UFAM. Mestre em Letras, na área de concentração em Estudos Literários, pelo Programa de Pós-graduação em Letras, PPGL/UFAM. Especialista em Educação, Pobreza e Desigualdade Social pela Faculdade de Educação, FACED/UFAM. Graduado em Letras pela Universidade Federal do Amazonas. Graduado em Pedagogia pela Universidade Nilton Lins. É professor da Secretaria de Educação de Manaus, atuando como assessor pedagógico interdisciplinar.

Orcid: https://orcid.org/0000-0002-9667-9454

E-mail: leandro-vasconcelos@outlook.com

Diego Fernandes Pinheiro: Mestrando em Educação pela Universidade Federal do Amazonas. Graduado em Pedagogia na Universidade Federal do Amazonas com habilitação em Orientação Educacional e Supervisão Escolar.

Orcid: https://orcid.org/0000-0002-9787-1608

E-mail: diegoufam4@gmail.com

Este periódico utiliza a licença Creative Commons Attribution 3.0, para periódicos de acesso aberto (Open Archives Initiative - OAI). 